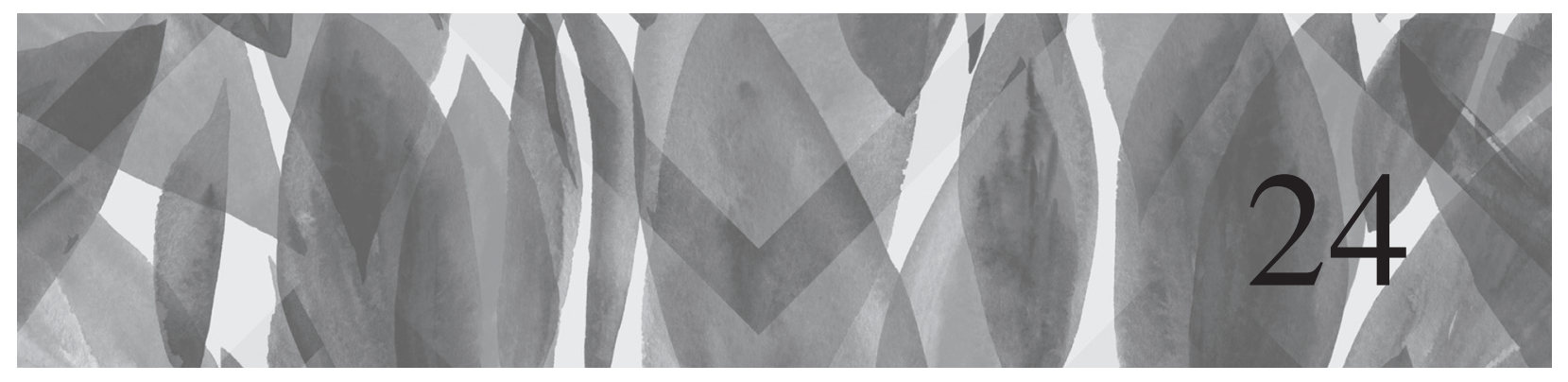

\title{
Teaching Diverse Learners in Europe: Inspiring Practices and Lessons Learned from Germany, Iceland, Lithuania, Luxembourg, Spain and Sweden
}

Justin J.W. Powell, Kerstin Merz-Atalik, Stefania Ališauskiené, Michelle Brendel, Gerardo Echeita, Hafdís Guðjónsdóttir, Jóhanna Karlsdóttir, Lina Milteniené, Rita Meliené, Edda Óskarsdóttir, Bengt Persson, Elisabeth Persson, Cecilia Simón, Marta Sandoval, Anneli Schwartz, Heike Tiemann and Katja Weber

\section{INTRODUCTION: INCLUSIVE EDUCATION VALUES: FROM GLOBAL NORM TO LOCAL REALITIES}

Inclusive education has become a global goal. This aim is supported by the recognition of the human right to education for all and the vision of democratic society that values diversity in all its facets. Engaging pupil diversity to enhance learning remains a challenging task for teachers in schools everywhere, as education for all is extended to become universal. Yet successfully supporting diverse pupils in their learning processes has always been at the heart of outstanding pedagogy. Across Europe we find significant variation in both the extent and the quality of inclusive schooling based on a range of institutionalized structures and 
cultures evident in the organizational settings and teaching practices of heterogeneous education systems (European Commission, 2017). Promoting the cooperation of scholars, policymakers, and practitioners in places with differing traditions in (more or less) inclusive schooling is simultaneously a key task for comparative researchers and a key goal for European education decision-makers.

Building upon a three-year collaboration in the European-Union-funded Comenius Network Project 'Teaching Diverse Learners in School Subjects' (TdiverS), this chapter synthesizes lessons learned about 'inspiring practices' of inclusive education found in schools in the six participating countries of Germany, Iceland, Lithuania, Luxembourg, Spain, and Sweden. The project focused on contemporary practices in teaching the diversity of learners and involving all actors in schools into the reform process, building on three pillars of diversity (see Project Annual Reports: TdiverS, 2015, 2016, 2017). The first comprises diversity in theoretical and practical knowledge resulting from collaborations of practitioners and scholars exchanging knowledge and experiences in teaching school subjects in inclusive settings from diverse perspectives. Secondly, the project strengthened the awareness of diversity in frameworks, conditions, and determining factors of teaching inclusively in six countries spread across Northern, Eastern, Southern, and Western Europe. Thirdly, inclusive education research builds upon and benefits from - engaging multilevel, multicultural, and multidisciplinary perspectives. The chapter highlights the values of inclusive education, maps the contemporary geography of inclusive settings and practices across Europe, summarizes contemporary education reforms and the implementation of inclusive practices, and discusses the TdiverS project results, mainly a collection of videos of inspiring practices and lessons learned and related texts translated into English.

Since the worldwide ratification of the UN Convention on the Rights of Persons with Disabilities (UN CRPD), which clearly defines the right to inclusive education (in Article 24) - throughout the life course - all schools and education systems in Europe face the challenge of developing inclusive cultures, inclusive structures, and inclusive practices (see Ainscow, Booth \& Dyson 2006). Further, the 2030 Agenda for Sustainable Development defines as Goal 4 to 'ensure inclusive and quality education for all and promote lifelong learning' (United Nations, 2015). On 16 October 2015, a European Hearing entitled 'Inclusive Education Take Action!' was held, in the context of the Luxembourg Presidency of the Council of the EU, by the Luxembourg Ministry of Education, Children and Youth (MENJE), together with the European Agency for Special Needs and Inclusive Education. Seventy-two young people of diverse abilities from 28 countries attended this event, coming to consensus on five key messages: (1) 'everything about us, with us': meaning that young people should be directly involved in all decision-making concerning them; (2) barrier-free schools - physical and technical barriers should be eliminated; (3) stereotypes need breaking down and critical reflection is required on the concept of 'normality'; (4) 'diversity is the mix, inclusion is what makes the mix work'; and 5) becoming full citizens relates to the impact of inclusive education with regard to becoming fully included in society (EASNIE, 2015). Embedded within institutionalized education systems, such fundamental reform processes to further develop inclusive education systems depend on the strategies and practices that teachers in ordinary classrooms engage with and apply in facilitating learning opportunities within classes consisting of a diversity of learners (see, e.g., Prengel, 2016).

Three main elements that have driven this research and our cross-cultural collaboration are: (1) the nexus of theory and practice, with the explicit intention to provide theoretically guided reflections of 'inspiring practices' of inclusion in subject teaching by collecting 
experiences in instruction of school subjects in inclusive classrooms, and to enable teachers and others working in or related to education to engage in a dialogue on national and cross-national levels (and thus contribute to bridging the gap between theory and practice); (2) the goal of gaining new perspectives by sharing research findings and concrete experiences of inclusive education (in school subjects) and teacher education reforms related to inclusive education in different countries; and (3) the aim of reflecting and establishing common concepts for training teachers in inclusive education as well as knowledge regarding specific subjects and of facilitating inclusive teacher education - realized in a collection of videos on a USB flash drive distributed worldwide free-of-charge (see http://www.tdivers.eu/).

In terms of values, the emphasis was on valuing learner diversity - considering learner diversity a resource and an asset to learning processes - and on supports that ensure that all pupils may learn together and that teachers maintain high expectations for all learners (Hart et al., 2004; European Agency, 2012). The cross-national research collected students', teachers', and principals' attitudes and experiences, examples of effective teaching approaches in heterogeneous classrooms in different school subjects that may serve as inspiration for teachers in other schools, also located in other countries, understood as a key motive behind crossnational comparative studies on (inclusive) education (see, e.g., Richardson \& Powell, 2011; Powell, 2014).

\section{MAPPING THE GEOGRAPHY OF INCLUSION IN EUROPE}

The TdiverS project resulted in recognition that despite considerable differences in education systems across Europe, inclusive educational practices are everywhere to be found. In the project site visits, we found inspiring inclusive practices in Germany, Iceland, Lithuania, Luxembourg, Spain, and Sweden, despite their contrasting overall levels of inclusive education and education systems more generally. While Europe has diverse cultures and languages, the desire for cooperation across boundaries, be it cultural, linguistic, disciplinary or professional, was evident - as was the need to collaborate to successfully understand inclusive practices and facilitate them in such diverse contexts. Three years of extensive exchange - via country study visits, school visits, sharing the videographic examples of practice, and through international conferences and consortium meetings at least twice a year in Europe and North America (project meetings and presentations) - enabled us to grasp more fully both convergence and divergence in the on-going processes of developing more inclusive schooling across Europe. To recognize these common and different understandings required time for in-depth dialogue and benefitted tremendously from joint exploration of varying schools, systems, and cultural contexts (see Artiles et al., 2011). Attention to different levels was crucial, as country-level aggregated data (macro level) used in many cross-national analyses did not match regional or local experiences and practices manifest during the school visits that facilitated our cross-cultural analysis and videography (on the meso and micro levels of individual schools and individual classes).

Reflection of different levels of education policymaking and reform as well as analysis and evaluation and disaggregation of national data, especially in federal systems, was necessary. In fact, some of the schools with which we collaborated remain among the few schools that have oriented themselves to inclusion, even when this is contrary to the system logic of the education system, oftentimes implying persistent segregated or separated provision for pupils considered to have special educational needs (e.g., Powell, [2011] 2016). The recognition and responses to educational and social 
disadvantages - and which students 'have special educational needs' and 'become disabled' in schooling and/or upon transitioning to adulthood - depend significantly on the institutionalization of the education system and social welfare programs. Where and when the general exclusion of pupils with impairments has been overcome through the development of special education programs, these nevertheless frequently exhibit an overrepresentation of children living in poverty or in families with low socioeconomic status; boys and ethnic minorities (and children from migrant families from certain countries) are often considerably overrepresented (see Tomlinson, 2017).

Comparing the TdiverS partner countries, we found a remarkable range in classification rates of pupils in special education in 2014 (measured as the percentage of pupils with SEN out of total school populations), from $0.5 \%$ in Sweden to over $16 \%$ in Iceland (European Agency, 2017a). This contrast, found even among the Nordic countries that are considered some of the most inclusive worldwide, is remarkable in highlighting very different ideas relating to classification and learning opportunity structures (see Powell, [2011] 2016; Biermann \& Powell, 2014). Also, the statistics collected from each country differ according to classifications and procedures and reporting to the European Agency for Special Needs and Inclusive Education (EASNIE), an EU-funded organization that has done most to develop comparative studies and collaborative development projects in special needs and inclusive education (and provided the data presented herein).

Across the six partner countries, the necessity of being diagnosed, often a condition for receiving additional support, differs very widely - and this demands attention to the dilemma of balancing the positive provision of resources and the negative consequences of labeling that are prevalent throughout education systems, most of which demand classification as a prerequisite to receiving individualized support and services. The classification terms (categorical labels) are highly connected to the segregated special schools (e.g., in Germany) or to the system of providing special education support (e.g., depending on the availability of internal professional resources in inclusive schools or the need for ambulatory support for pupils with SEN). In many countries - both larger and smaller, richer and poorer - we find persistent educational and social disadvantages suffered especially by children and young people with impairments and disabilities, but also by those in need of support in achieving set learning goals; these groups are not the same (see, e.g., Richardson \& Powell, 2011).

Among the major barriers to inclusive schooling are expanded and highlydifferentiated systems of segregated special schools and separate classrooms. Comparing the proportion of pupils of the total pupil population in segregated settings across selected European countries and TdiverS partner countries reveals the considerable range - from almost no school segregation in Sweden and Spain with less than $1 \%$, to Iceland, Lithuania and Luxemburg in the lower middle range between 1 and $2 \%$ - to Germany at the upper end with nearly $4 \%$; the quotas of children in segregated schools and separate classes varies between almost none in Italy and Malta to over 7\% in Belgium (data from 2014, see European Agency, 2017a). Throughout Europe, countries have developed different constellations of support services and organizational forms to provide for children with disabilities or students with learning difficulties and those that suffer myriad disadvantages and discrimination. Despite global normative pressures, there has been limited global convergence in special and inclusive education over the past decades (Richardson \& Powell, 2011). Thus, inclusive education reforms must explicitly address the varying institutionalization of special (needs) education and its persistence if these change processes are to succeed. 


\section{INCLUSIVE EDUCATION REFORMS: FROM POLICY INITIATIVES AND RESEARCH TO SUSTAINABILITY IN SCHOOLS}

In charting the development of inclusive education reforms especially, scientific attention to the gap between policy rhetoric that often subscribes to human rights and international norms (as codified in the UN-CRPD, i.e., Article 24, or the Sustainable Development Goals, i.e., SDG 4 Quality Education) and school realities is crucial. The normative dimension of human rights charters has succeeded in broad-based awareness-raising about inclusive education but has also called forth counter-pressures that show backlash as well (Powell, Edelstein, \& Blanck, 2016). Yet in the participating countries, even the most successfully inclusive, the school and its leadership and teachers require support, resources, and networking opportunities across borders as they become change agents. This valorizes the schools' provision and practices in the face of contrasting system logics: inclusive schooling is not compatible with segregated structures and settings, yet these remain ubiquitous in many countries. Thus, inherently, inclusive education has to be realized as an ongoing (political) process and as a goal, rather than a once attained and stable status. The challenges for inclusion are historically and regionally shifting, as they relate to contexts and therefore differ according to (levels within) education systems. As a process, it is inherently challenging and has political implications. TdiverS provided learning opportunities to understand that many of these challenges faced across Europe are similar; no school or country is alone in facing them.

Where such reforms have progressed, they should not be taken for granted, as these reform processes and the inclusive values undergirding them are always at risk of being stopped or rescinded. Thus, both researchers and practitioners must attend to the sustainability of the implementation of reforms aiming to make schooling more inclusive. Modelling inclusion in schools was found important, namely for all involved to 'live' inclusion, including such features as neighborhood outreach programs, students' and parents' active participation in school development, school charters signed by all members of the school, ethical leadership (Harris et al., 2017), and team-teaching to provide adult role models for collaboration and inclusive practices within the school. Indeed, a key method for bolstering the sustainability of inclusive schooling is to rely on the dialogic principle, ensuring communication among all stakeholders and all those participating in the life of the school and the education of the next generation.

Research and studies of implementation are crucial to bolster such processes. As a project funded by the European Union, the TdiverS project exemplifies cross-national and multicultural exchange and networking that facilitates the diffusion and dissemination of ideas related to inclusive education, enhancing its sustainability. The nearly twenty individual project partners included representatives from universities, teacher training organizations, educational administrations, and schools, and the additional associated partners from policy who collaborated for over 36 months (2013-2016) on the preparation of different sets of materials, relying on multidisciplinary inquiry, a mixture of methods, and multiple languages. Key sources were country reports written by project members, school visits, communitybased discussions with reference groups (for example, young people with disabilities), international public and professional association conferences, and many discussions among consortium members and with the teachers involved in the videography production, as well as project guests, especially teachers from the six countries and related EU research projects. This facilitated the project goal to identify principles for inclusive teaching and learning that could be shared 
and reviewed by the partners to help select the 'inspiring practices' found in the partner schools for dissemination across Europe and beyond.

We now turn to discuss the implementation of inclusive education and the lessons learned in comparative perspective.

\section{DIVERSITY, DIFFERENCES, DISPARITIES: IMPLEMENTING INCLUSIVE EDUCATION IN SIX EUROPEAN COUNTRIES}

The study emphasized the diversity of learners, cross-national and within-country differences, and disparities in learning opportunities, all related to inclusive education reforms in various stages of implementation across the six European countries. In systemic terms, inclusive education was understood to be an overarching, comprehensive change project. For more inclusive systems, furthering inclusion means eliminating altogether the separation of pupils into ability-based groups within the general school or classroom. In less inclusive systems, such developments as ambulatory services facilitate inclusive schooling in the short term by reducing the need to segregate or separate pupils to provide support services, although special schools continue to exist to some extent in all countries - in some serving the majority of pupils with SEN, as in Germany, while in others serving only a minority of pupils with SEN, as in Iceland, Lithuania, Luxembourg, Spain, and Sweden, although classification rates also vary considerably (see European Agency, 2017a). The spatial component of schooling is crucial, as schools should be living spaces that promote well-being and provide various learning opportunities. Changes in curriculum and school life to reflect inclusive principles affect the whole school and the entire school culture, requiring the school to be open and embedded in its community. Teachers in countries with comprehensive schools for all pupils have more experience in explicitly teaching heterogeneous learning groups than those within stratified systems and multiple secondary school types (Merz-Atalik, 2016).

In terms of learning processes, assessments for learning, and diagnostics (Merz-Atalik, 2013a; Prengel, 2016) were found to be crucial as barriers to or facilitators of inclusion, since competence-focused assessments, being deficit-focused, often lead to labelling, and thus counteract inclusive education principles. The importance of every pupil having an individualized education plan was emphasized and some schools have found ways to de-emphasize the overreliance on competence measures and devise alternative assessments, such as portfolio work that all learners produce and share with their classmates, encouraging peer-to-peer interaction and learning (Brendel \& Noesen 2014). Yet, especially at transitions, prevailing system orientation and norms lead to problems for individual teachers and pupils, thus inclusive education must be a system-wide reform.

Subject teaching was discussed as possibly limiting inclusion in contrast to multidisciplinary, project-based work and open structures that facilitate inclusion. Not all (subject) teachers are equally open to inclusive schooling, because their expertise may be threatened or learner diversity demands more complex preparation of learning materials. Subjectspecific learning standards should be personalized, according to individual pupils' profiles, yet subjects are often still taught quite traditionally in teacher training programs.

The project itself exemplified challenges in policy learning to support inclusive practices, programs, and policies. Regarding project management, three years is an arbitrary duration and it raised the question of the optimal time-span for the development of ideas and collaboration with such a wide scope and ambitious goals. Fortuitously, TdiverS was built largely upon existing networks (European Agency Project 'Teacher Education for Inclusion' TE4i) and earlier research collaborations between individual partners. Yet, 
fundamental discussions were necessary to develop a common language and decide priorities and task distribution. Differences in outlook and perspective remained, and these are probably unresolvable. For example, in the German-speaking countries, didactics in subject areas (so-called Fachdidaktiken) are considered independent fields and departments within universities, often separate from teacher training in general education or special education. In other countries, this gap is less pronounced or even nonexistent. As in schooling, the project partners accepted these differences, recognizing the value in them (and the contexts that gave rise to them).

\section{INSPIRING PRACTICES AND LESSONS LEARNED IN GERMANY, ICELAND, LITHUANIA, LUXEMBOURG, SPAIN AND SWEDEN}

Aspiring to catalogue 'inspiring practices', instead of a single 'best practice' across Europe, the team discovered how complex and intensive videography is, especially in very different school settings in diverse cultural contexts, in six different languages, and with varying expertise and technological tools. The team learned that the videos need a framework for understanding the context, to understand the message behind the selected situation(s) and its determinants - barriers and facilitating factors posed by the education system generally and the school environment more specifically. The videos and reviews and translations of key scholarly texts were contrasting goals and aspects that needed to be reflected (i.e., videos of and for praxis and teacher education were selected on different criteria than scientific literature), although the project output integrated literature lists and texts and videos to provide for diverse potential uses and users. A key lesson learned was the necessity to explicitly discuss the definitions and values of inclusive education and reflect more broadly on the contribution of comparative methods to such studies.
Collaboratively, we raised questions about the purpose of education and teaching in a broader perspective. Across Europe, the perceived importance of evidence-based policymaking and notions of quality, excellence, relevance, and impact have risen, even as the EU extends its role in establishing cross-border networks and in shaping research agendas by offering incentives to align research agendas to overarching priorities and themes - and collaborate interculturally - in EU projects (Zapp, Marques, \& Powell, 2018). Today, competitiveness is continuously monitored by comparative indicators used by policymakers, scholars, and administrators to generate reform goals, to identify standards and good practices, and to empirically verify policies and programs. Increasingly, countries have enacted policies that emulate - or are legitimated by reference to - successful foreign models. Mechanisms of such cross-cultural transfer include 'continuous competitive comparison' in such forms as rankings, benchmarking, and best practices; policy learning and networks; and intergovernmental negotiation and supranational coordination. Supranational coordination facilitates the definition of standards, extends cross-border mobility, and enables collaboration. Such collaboration and cooperation, sharing 'inspiring practices' from inclusive learning environments, and learning from reform processes and experiences elsewhere is crucial. Indeed, teaching diverse learners in school subjects is a challenge for all teachers. Since the TdiverS final conference in Ludwigsburg, Germany, in 2016, the video collection (USB flash drive) has been presented and viewed widely and is increasingly utilized in teacher education - in the partner countries and beyond. Such projects and the collection and dissemination of inspiring practices in inclusive education are crucial for countries in need of professionalization to enable more inclusive teaching and 'pedagogy of diversity' (Prengel, 2016). We next provide sketches of the country contexts and lessons learned. 


\section{Germany: The Paradox of Developing Inclusive Education and Co-teaching without the Decline of Special Schooling}

Germany's rather short history of inclusive education begins with pilot projects in several Bundesländer in the 1970s. In 1994, the Standing Conference of Ministers of Education and Cultural Affairs (KMK) first published a recommendation that 'the education of disabled young people is in principal increasingly a cooperative task of all schools. Special education should be understood as a necessary addition and key element of providing general education'. Despite terminological change from the 'need to attend a special school' (Sonderschulbedürftigkeit) to 'special educational needs' (sonderpädagogischer Förderbedarf) in policy documents, the reality remains that the majority of pupils with SEN still attend segregated special schools (see European Agency, 2017a). Since 2009, the UN CRPD is legally binding in Germany, yet the 16 Bundesländer maintain authority over schooling and interpret the ideal of inclusion in their existing systems very differently: while some protect the existing special education institutions, others strive for and implement broad inclusive education reforms (Powell, Edelstein, \& Blanck, 2016). Special education support systems have different profiles depending on regional conditions. Policy mandates the professional organizational development of special needs education, counselling, and support, including preventive, inclusive, and cooperative forms (KMK, 2011). Most Bundesländer guarantee the parental right to choose the school for their children; however, this led to debates, including arguments for preserving special schools, a major barrier to inclusive education reform.

Although inclusive education is developing gradually in Germany, this is taking place without the decline of special schooling in most Bundesländer, a paradox that reflects heightened norms and expectations, defined standards, as well as the awareness of and diagnosis of SEN (Powell, [2011] 2016). The inclusion rate (students with SEN in inclusive settings of all students with SEN) ranges considerably between the 16 Bundesländer, from $83 \%$ in Bremen to $25 \%$ in Hessen, as does the special school participation rate of all students, ranging between $6.5 \%$ in Mecklenburg-Vorpommern to $1.2 \%$ in Bremen (Autorengruppe Bildungsbericht, 2016). Despite UN CRPD ratification, segregation rates even increased from 2012 to 2016 in some Bundesländer.

Inclusive education and didactics lag behind due to factors such as: divisions between the disciplines of general education, special education, and subject teaching in universities and the highly segregated education system; the challenge for inclusive education researchers to find inclusive settings to analyze, even where states permitted or even funded such research (Merz-Atalik, 2013b); and the very recent recognition of the need for the education and training of all teachers in preparing individualized education plans and mastering inclusive teaching approaches (Merz-Atalik, 2014). In 2015 the KMK and the German University Rectors Conference (HRK) adopted recommendations for teacher education for an education system that embraces diversity, stating that the development of schooling that recognizes and values diversity as a strength and as 'normality', is a goal of teachers in all schools.

The two TdiverS partner schools are rare cases of inclusive education in the Land Baden-Württemberg, which started to develop comprehensive schools only in 2013 and has a long history of selective and stratified secondary schooling (segregation among school types after primary education, from grade 4). Yet their expertise in cooperating as coteachers (exemplified by Sabine Meixner, primary school teacher, and Kerstin Bohl, special education teacher in the Pattonville Primary School Ludwigsburg) and competence in personalizing their subject-related teaching, relating it to the diversity of their students 
(exemplified by Markus Plath, teacher of physical education in the Comprehensive School Tübingen), prove crucial as inspiring examples, especially in this national and state context. This confirms that positive attitudes and the self-motivated professionalization of individual stakeholders act as significant resources for inclusive education reform. The question remains: How to strengthen this engagement in on-going reform processes?

We now turn from the least to most inclusive education system and from the largest to the smallest country in our sample.

\section{Iceland: Equalizing Opportunities and Improving Student Well-Being in Inclusive, Student-Centered, Collaboration-Oriented Schools}

Following educational legislation in 2008 mandating that all schools should be inclusive, a new national curriculum for early childhood, compulsory, and upper secondary education came into effect in Iceland in 2011 (Sigurðardóttir, Guðjónsdóttir \& Karlsdóttir, 2014). The curriculum guide shifts from detailed objectives towards a focus on learning outcomes and foundational educational ideas. This national curriculum is based on six fundamental pillars: literacy in the widest sense; education for sustainability; democracy and citizenship; education for equality; creativity; and health (Icelandic Ministry of Education, Science and Culture, 2011). Recently, the European Agency for Special Needs and Inclusive Education has externally audited the Icelandic education system, targeting areas to improve (EASNIE, 2017b).

As elsewhere, teachers in Iceland continuously search for pedagogical approaches to meet both curricular demands and student diversity in inclusive schools. Teachers who participated in the TdiverS project organize their subject teaching in diverse and inclusive classrooms. In their responses to diverse students, three main themes emerged: (1) how the teachers understand inclusive education and how that affects their teaching; (2) how teachers organize and prepare their teaching in different subjects for diverse students; and (3) the importance of collaborating with other teachers and support staff in creating inclusive environments.

The conceptual understanding of inclusion, as explained by the teachers, is characterized by their view that students' well-being is the most important goal of inclusive schools taking care that everyone is supported to achieve their goals, accomplished by providing equalized opportunities for students to show, grow, and enjoy their various strengths. Attending to the differences between students, as well as their commonalities, is vital as inclusive education demands that teachers use diverse teaching methods.

In preparing and organizing teaching and learning, the teachers emphasize the importance of thinking about the whole group and of adjusting their planning to each unique group of students. In their preparations these teachers take into account students' interests and motivations in wanting to do the assignments. They have found that group work, playing games, and having fun learning has positive effects on students' success in school.

Collaborating with others was emphasized as important for reaching all students. With the support of special educators, teacher assistants, and social educators, the teachers stated that they were able to create learning spaces that could include all of their students, provide needed differentiation, and meet students' individual needs. As one of the teachers explains: 'When I work with the special needs teachers, I first decide on an assignment and then I get them to review it for me and find ways to adapt it for some students. This collaboration has been very successful. It makes my life and work a little easier'. The practices of teaching diverse pupils are grounded in pedagogy that integrates professional knowledge about teaching, learning, and child development, and involves an ethical and social commitment to children (Guðjónsdóttir, 2000). 
Inspiring teaching practices promote inclusion, honor diversity in and of cultures and ethnic experiences, and build the learning environment around the different contributions and identities of each student. These teachers are generating inclusive pedagogy that is student-centered and characterized by openness towards student diversity, the use of innovative strategies, and building upon collaborations in schools and beyond.

\section{Lithuania: Teachers Supporting Learners as Collaborative Partners in More Personalized, Accessible Classrooms}

The main ideas concerning inclusive education and the inclusion concept are stated in strategic national documents, such as the Law on Education (2011) and the National Education Strategy 2013-2022. Equal opportunity is one of the principles upon which the education system is based, aiming to ensure equality for individuals with variations in abilities, gender, race, nationality, language, origin, social context, religion, beliefs, or convictions. The Strategy states the priority to create opportunities for the education of children with different abilities and needs and to ensure that each individual has access to education and opportunities to attain a general education. The Strategy defines goals for the development of education, and the means for achieving these goals, and establishes key quantitative and qualitative outcome indicators to be used as the basis to further develop the Lithuanian education system and its evaluation. Learning opportunities for children of ethnic minorities and of migrant families shall be ensured and the system of support for children and young people with exceptional abilities shall be developed and expanded.

Since the post-Soviet transformation, many studies have been conducted with a focus on the inclusive education of children with special educational needs. In most of these studies, general principles of inclusive education, quality of educational assistance, support for different groups of children having special educational needs, collaboration, and the role of teachers and specialists, and teachers' attitudes have been analyzed (see, e.g., Ališauskas et al., 2009; Milteniene \& Venclovaite, 2012; Ališauskas, Ališauskienè, \& Milteniene, 2013). The conceptualization of inclusive education in Lithuanian research includes addressing special needs education explicitly.

The success of inclusive education is largely related to the accessibility of resources and educators' abilities to identify and share them to facilitate learning processes. Teacher competencies and readiness are among the most important factors in developing favorable environments and quality education for every learner (Ališauskas, Ališauskienè, \& Milteniene, 2013). TdiverS provided learning opportunities to understand that many challenges facing schools are similar, with school representatives, especially Renata Geleziniene, Kestutis Saltis and Saulius Vilutis, contributing to the project's findings. Recent research has been based on new paradigms and methodologies, such as collaborative teaching and learning, and personalized teaching and learning, among others. This new paradigm guides the whole education system to acknowledge the changing needs and roles of the learner, moving from viewing the learner as 'the user' to seeing the learner as 'collaborating partner'. In this context, supporting the unique learning path of each student is seen as the focus of inclusive education.

\section{Luxembourg: Intersectional Inclusion and Dialogic Teaching in Culturally Diverse, Multilingual Schools}

Luxembourg lies at the crossroads between Europe's Germanic and Francophone language communities. With among the most culturally and linguistically diverse populations in Europe, Luxembourg's pilot projects 
in inclusive education must be evaluated from an intersectional perspective, considering myriad characteristics (Powell, LimbachReich \& Brendel, 2017). As across Europe, a century ago, exclusionary practices were widespread, as was the orientation towards average learning progress in general schooling. Especially following the universalization of compulsory schooling, responsibility extended to include increasingly diverse student bodies, but specialized organizations serving people with perceived sensory or intellectual impairments often led to stigmatization and segregation. After World War II, the idea of education as a human right diffused globally, ultimately resulting in calls for 'Education for All' and inclusive education worldwide. In Luxembourg, such demands for more equity in schooling have long been present, exemplified by the Luxembourgish government campaign called 'A School for Everyone' in the 1970s.

Despite many efforts over the past decades, such as comprehensive school reform, these have not succeeded in bringing about fundamental changes in schooling to enhance equality. In fact, researchers find considerable persistence of social and school segregation, in disparate school performance results, and in high levels of grade retention and school dropout (Luxembourg Ministry of Education, Children and Youth 2016) - not uncommon patterns among Luxembourg's neighboring countries of Belgium, France, and Germany. New laws and decrees and many projects and initiatives, along with education expansion, dramatic demographic growth, and social changes in society have shifted the context for schooling. Luxembourg has signed international human rights treaties that reflects global norms, yet the school system structures have not fundamentally changed.

Nevertheless, a number of school projects have developed to foster inclusive learning environments, including pre-primary and primary schooling in Esch/Alzette (1995-2000), the primary school Weiswampach (2000), the Eis Schoul on Kirchberg (since 2008), and the
Institute for the Visually Impaired), as well as TdiverS partner school Ecole Jean Jaurès in Esch/Alzette (since 2006). In that all-day school, inclusive practices have developed, based upon long-term collaborative teacher research to create a community of learners and offering multiple approaches to language learning in preschool and to develop an inclusive approach for all pupils across school subjects. An open architectural structure and lesson plan, a consensual school charter, alternative assessments, portfolio work, and a narrative approach to teaching and learning are among the key aspects of making schooling more inclusive in Luxembourg (Brendel \& Noesen, 2014). For example, narrative assessments may show what a child knows and how learning activities fit best into a child's universe of knowledge, as well as facilitating children's expression and communication, while positioning them as experts of their own learning. The TdiverS video, co-directed by pupils, collected inspiring practices as it demonstrated dialogic, dialectical ways in which teachers and students interact, providing a guide to their vision and understandings of 'inclusion' lived in their school community.

\section{Spain: The Values of Inclusion and Ethical Leadership to Foster Collaboration Among All Stakeholders}

Spain has a territorial and political structure composed of 17 Autonomous Communities and two Autonomous Cities (Ceuta and Melilla), with a wide range of management and direction of their own educational policies, within a common state law (LOMCE, 2013), very similar to Germany's Bundesländer. Therefore, as in that country (Powell, Edelstein, \& Blanck, 2016), the differences between Autonomous Communities in terms of commitment to inclusive education are notable. Yet the current framework law has among its guiding principles a clearly 
inclusive approach: Art. 1. Equity, which guarantees equal opportunities, educational inclusion and non-discrimination, so that education acts as a compensating element for personal, cultural, economic and social inequalities, with special attention given to those resulting from disability. This legal recognition is related to Spain's long commitment to 'inclusion' since the mid-1990s, reflected in the 1994 World Conference on Special Needs Education: Access and Quality (UNESCO, 1994) held in Salamanca, Spain (Saleh, 2004).

However, as pointed out in relation to other countries (Ainscow, 2016), and acknowledging the important advances in the educational integration of students most vulnerable to exclusion (those considered to have SEN), the large gap between formally established commitments and reality is tenacious (Echeita, 2017). Simultaneously, throughout the country, and similar to other TdiverS participating countries, there are many inspiring examples of the possibility of inclusive education contributing to the development of a society with greater social justice.

We have closely worked with three schools in Madrid to identify the central elements that have been changed in their school cultures, policies, and pedagogies (Booth \& Ainscow, 2011; Florian \& Linklater, 2010), trying to welcome and recognize them, and responding with measures to bolster equity and value the diversity of the students who attend these schools (Simón et al., 2016). Within a collaborative approach among school staff and researchers from universities (Messiou, 2017), focus groups were held to discuss these questions and results subject to qualitative content analysis.

Following Tyack and Cuban's (1995) analysis, the development of more inclusive education does not fit into the 'grammar of schooling' framework that has defined our formal education systems. The results show the main barriers and challenges the schools face(d) in advancing these change processes towards reaching their aims: of a dialogical culture among stakeholders, driven by strong inclusive principles and values; more collaborative work among teachers (including those with support roles), not only to prepare class lessons but also within the classroom to implement them; emphasis on cooperative work among students; multidisciplinary, project-based work in school subjects; and flexible structures to adjust to learning needs and expectations.

The most important lessons learned from those schools is that ethical leadership, collaboration among stakeholders at all levels, and adequate school conditions are necessary to break and replace existing barriers, school structures, curriculum, and assessment practices. If this is not done, inclusive education will remain an ideal beyond the reach of schools.

\section{Sweden: Respect for Diversity, Tolerance, and Solidarity Fosters Inclusion to Facilitate Equality and Achievement}

In 1960, the Swedish Parliament passed a bill to establish a nine-year compulsory school system for all children. A one-year preschool that children attend from six years of age stimulates pupils' development and learning, preparing them for further education. Parliament has made this introductory year mandatory from the academic year 2018/2019, with compulsory school now lasting ten years. While the term 'inclusion' is used only sparingly in policy texts, such as the School Act, the School Ordinance, and national curricula, it has also been abused in political contexts. Simultaneously, inclusion is the subject of lively and intense discussions in municipalities and in schools, which are often creative in adapting the concept to local realities.

In the municipality profiled in TdiverS, the vision statement is entitled 'A learning environment for everyone - a modern school on scientific grounds'. The participating school builds upon all staff working together to create a good learning environment in 
which every child develops as far as possible according to his or her own ability - using an inclusive approach. This means combining curricular knowledge goals with democratic education, with concepts and principles such as justice, trust, and participation at the core, viewed as crucial as the pursuit of developing students' future ability to solve problems. Pupils in need of special assistance receive their main supports within the framework of regular education. Teachers make additional adjustments to meet the students' different needs. An example is alternative communication techniques used in parallel with spoken language, with classmates learning to use signing support, which in turn facilitates the social aspects of school days. Other examples are to vary the teaching methods and use ICT in various forms, always with a clear focus on students' knowledge development in the various subjects. Students with different types of diagnoses or learning difficulties can also participate in the general teaching instruction together with their classmates. Specialist teachers can also work together with subject teachers in the classroom if and when needed.

Another Swedish study portrays a municipality that has transformed itself. Within three years, it rose from a position at the bottom of the national school league tables to the top - by implementing inclusive education reform. Indeed, inclusion is not only justifiable from equality perspectives, as it can also help all pupils succeed and improve their achievement (Persson, 2013). School activities took their starting point from the UN Universal Declaration of Human Rights and our common responsibility for sustainability in a global perspective. A social capital framework was used to interpret the students' perspectives and experiences and revealed the strong norms and values to which the students were exposed, and the bonding, bridging, and linking practices that connected them to one another meaningfully (Schuller, Baron, \& Field, 2000). A sample of 20 students was interviewed about their experiences in this fully inclusive learning environment, with students articulating a strong commitment to helping others to succeed and conveying a clear understanding and confidence about themselves as learners. They valued respect for diversity, tolerance, and solidarity with the most vulnerable, and took mature approaches to their own roles in a challenging future. These findings generate implications for practice, including an understanding of inclusive education as necessary to help young people to actively work for a sustainable world in an uncertain future.

\section{IMPLICATIONS FOR RESEARCH AND POLICYMAKING IN INCLUSIVE EDUCATION}

In sum, we find that descriptive aggregate statistics mask paradoxes, such as the professional engagement in and development of inclusive education and co-teaching without declining rates of special schooling overall (Germany). Even in a system of inclusive, student-centered, collaboration-oriented schools, equalizing opportunities and improving student well-being remains a key goal for school development (Iceland). When teachers support learners as collaborative partners, especially in well-resourced, more personalized, and accessible classrooms, schooling improves (Lithuania). Inclusion from an intersectional perspective and dialogic teaching in culturally diverse, multilingual schools is facilitated by alternative assessments, portfolio work, and studentcentered pedagogy (Luxembourg). The values of inclusion and ethical leadership to foster collaboration among all stakeholders is crucial for inclusive education to develop over the long run (Spain). Students are ready to respect diversity, promote tolerance, and support solidarity, which fosters inclusive education that in turn facilitates equality and achievement (Sweden). The scholarly significance of these findings derived from research and practice have been published as material 
for teacher education in English and the halfdozen languages represented by the partner countries, including a collection of multilingual, multidiscplinary resources on teaching diverse learners in school subjects in inclusive settings (TdiverS USB flash drive).

This contribution briefly synthesized our experiences and lessons learned from years of collaborative work with the selected schools and teaching teams on effective concepts, didactics, and methods of teaching - in order to assist teachers' teaching and learners' development in inclusive classrooms. Stakeholders, policymakers and the public were involved in the project through public conferences and the open-access publication of (preliminary) findings.

In the participating countries, we worked collaboratively with universities, teachertraining organizations, and selected schools, teachers, principals, and parents. During the cooperative process and dialogue with reflective practitioners, parents, and pupils from the inclusive schools, we gained useful knowledge about inclusive education. In some ways, teachers are often not aware of their true level of competences and inclusive practices developed in their everyday experiences. In the reconstruction through the dialogic approach, while discussing the video sequences of their own classroom practice, these competences and adaptations were often publicly reflected on for the first time. One team, consisting of a primary teacher and a special education teacher who work in an inclusive classroom (in Germany), summarized their experiences after a one-hour interview about their coteaching and teamwork by saying:

This was the first time we talked that intensively and explicitly about 'what we do' and 'how we do it', 'what we have learned', and this has led to a greater awareness about the things already professionally accomplished, but also about the things we need to learn much more about in the future.

Because the video sequences, and with them the teaching concepts and learning situations in the sequences, were authentically described by the teachers themselves, the (implicit) theories behind them were clearly defined. The presentation of personal practices as teachers, principals or as representatives of an organization (sometimes supported by or linked to theoretical resources) is among the project achievements that can make a difference in teacher education: experiential knowledge is made available for the training of other teachers; this is not often the case in teacher education materials.

We have considered that those involved in teacher education must reflect the ideals and the principals of inclusion - and its realization in specific contexts - to evaluate the concrete effects of teacher education curricula and coursework on competences to increase the level of confidence of pre-service teachers in teaching pupils with different levels and paces of learning development and performance in diverse groups and inclusive settings (Merz-Atalik, 2014). Alongside using videographic material of inspiring practices of inclusive teaching in curricula, it seems necessary to enable numerous and active professional experiences of the range of inclusive settings and strategies for all teachers to gain awareness about their crucial roles in fostering inclusion.

Cross-national collaborative projects like TdiverS promote in-depth comparison, cooperation, and understanding among representatives of countries with contrasting education systems and very different institutionalization pathways of inclusive schooling. Such exchange proves crucial in on-going inclusive education research and reform. In these six countries, professionals in schools and families emphasized the need to collaborate and exchange perspectives, with even the already most inclusive schools and communities regarding inclusion more as an on-going process than as an attained status. Resources from multiple sources and networking opportunities across organizational and institutional borders bolster progress in realizing more inclusive schooling. This is especially important in those contexts in which system 
logics remain focused on placement in special settings, which is incompatible with inclusive schooling. This also emphasizes the politics surrounding inclusive education, especially as the challenges shift over time and space. Comparisons provide learning opportunities to recognize similarities in the challenges faced that are ubiquitous across all levels, at the same time that differently successful reforms and 'inspiring practices' from elsewhere serve as models and support for innovation.

If inclusive reforms have progressed across Europe, but at different paces and to different extents, they should not be taken for granted, but rather valorized. Researchers, practitioners, administrators, and policymakers are responsible for ensuring the sustainability of implemented reforms that aim to make schooling more inclusive. Such change is in accord with the global norm of inclusive education as a human right and recognizes the benefits of diversity in education.

\section{REFERENCES}

Ainscow, M. (2016). Diversity and equity: A global challenge. New Zealand Journal of Educational Studies, 51(2), 143-155.

Ainscow, M., Booth, T., \& Dyson, A. (2006). Improving schools, developing inclusion. London: Routledge.

Ališauskas, A., Ališauskienè, S., Gerulaitis, D., Meliene, R., Milteniene, L., \& Sapelyte, O. (2009). Special educational support. Specialusis ugdymas/Special Education, 1(20): 131-143.

Ališauskas, A., Ališauskienė, S. \& Milteniene, L. (2013). Meeting children's special educational needs in school. A Lithuanian case. Society, integration, education: Proceedings of the international scientifical conference, May 24-25, 2013, Vol. II (p. 113-125). Rēzekne: Rēzeknes Augstskola.

Artiles, A. J., Kozleski, E., \& Waitoller, F. R. (Eds.) (2011). Inclusive education. Examining equity on five continents. Cambridge, MA: Harvard Education Press.
Autorengruppe Bildungsberichterstattung (2016). Bildung in Deutschland 2016. Bielefeld, Germany: W. Bertelsmann.

Biermann, J. \& Powell, J. J. W. (2014). Institutionelle Dimensionen inklusiver Schulbildung: Herausforderungen der UN-Behindertenrechtskonvention für Deutschland, Island und Schweden im Vergleich. Zeitschrift für Erziehungswissenschaften, 17(4), 679-700.

Booth, T., \& Ainscow, M. (2011). Index for inclusion. Developing learning and participation in schools (3rd ed.). Bristol, UK: CSIE.

Brendel, M., \& Noesen, M. (2014). Portfolioarbeit und Entwicklung inklusiven Unterrichts. In S. Schuppener, N. Bernhardt, M. Hauser, \& F. Poppe (Eds.), Inklusion und Chancengleichheit (pp. 244-255). Bad Heilbrunn, Germany: Klinkhardt.

Echeita, G. (2017). Educación inclusiva. Sonrisas y lgrimas. Aula Abierta, 46, 17-24.

Edwards, C., Gandini, L., \& Forman, G. (2012). The hundred languages of children: The Reggio Emilia experience in transition (3rd ed.). Santa Barbara, CA: Praeger.

European Agency for Development in Special Needs Education (2012). Profile of inclusive teachers. Odense, DK: EADSNE.

European Agency for Special Needs and Inclusive Education (2015). European hearing: Luxembourg recommendations - inclusive education take action! Odense, DK. https:// www.european-agency.org/sites/default/files/ Luxembourg_Recommendations_Flyer_ EN.pdf

European Agency for Special Needs and Inclusive Education (2017a). European Agency statistics on inclusive education: 2014 dataset cross-country report. (J. Ramberg, A. Lénrt \& A. Watkins, Eds.). Odense, DK: EASNIE

European Agency for Special Needs and Inclusive Education (2017b). Education for all in Iceland. External audit of the Icelandic system for inclusive education. Odense, DK: EASNIE.

Florian, L., \& Linklater, H. (2010). Preparing teachers for inclusive education: Using inclusive pedagogy to enhance teaching and learning for all. Cambridge Journal of Education, 40(4), 369-386.

Guðjónsdóttir, H. (2000). Responsive professional practice: Teachers analyze the theoretical and ethical dimensions of their work 
in diverse classrooms. Dissertation, University of Oregon.

Harris, J., Carrington, S., \& Ainscow, M. (2017). Promoting equity in schools: Collaboration, inquiry and ethical leadership. Abingdon, UK: Routledge.

Hart, S., Dixon, A., Drummond, M., \& Mclntyre, O. (2004). Learning without limits. Maidenhead, UK: Open University Press.

Icelandic Ministry of Education, Science and Culture. (2011). Aðalnmskr grunnskóla. Retrieved from http://www.menntamalaraduneyti.is/ utgefid-efni/namskrar/nr/3953. Reykjavík, Iceland: Mennta- og Menningamlarðuneytið.

KMK. (2011). Inklusive Bildung von Kindern und Jugendlichen mit Behinderungen in Schulen. Beschluss der Kultusministerkonferenz vom 20.10.2011. Bonn, Germany: Kultusministerkonferenz.

Lithuanian Law on Education, 2011-03-17 No XI-1281. http://www3.Irs.It/pls/inter3/dokpaieska.showdoc_l?p_id=407836

Lithuanian National Education Strategy 20132022 [2013-12-23 No XII-745]. http://www. smm.It/web/lt/teisesaktai/tei/valstybinesvietimo-strategija_1

LOMCE (2013). Ley orgnica para la mejora de la calidad educativa. https://www.boe.es/ buscar/pdf/2013/BOE-A-2013-12886consolidado.pdf

Luxemboug Ministry of Education, Children and Youth (2017). Les chiffres-clé de l'education nationale. Statistiques et indicateurs 2015/2016. Luxembourg: Ministère de l'Éducation nationale, de l'Enfance et de la Jeunesse.

Merz-Atalik, K. (2013a). Inklusion/Inklusiver Unterricht an der Gemeinschaftsschule. In T. Bohl \& S. Meissner (Eds.), Expertise Gemeinschaftsschule: Forschungsergebnisse und Handlungsempfehlungen für BadenWürttemberg (pp. 61-76). Weinheim, Germany: Beltz Juventa.

Merz-Atalik, K. (2013b). Der Forschungsauftrag aus der UN-Behindertenrechtskonvention Probleme, Erkenntnisse und Perspektiven einer Inklusionsforschung im schulischen Feld. In S. Trumpa, S. Seifried, E. Franz, \& T. Klauß. (Eds.), Inklusive Bildung: Erkenntnisse und Konzepte aus Fachdidaktik und Sonderpädagogik (pp. 24-46). Weinheim, Germany: Beltz Juventa.
Merz-Atalik, K. (2014). Lehrer_innenbildung für Inklusion - 'Ein Thesenanschlag'. In: S. Schuppener et al. (Eds.), Inklusion und Chancengleichheit. Diversity im Spiegel von Bildung und Didaktik (pp. 266-277). Bad Heilbrunn, Germany: Klinkhardt.

Merz-Atalik, K., Beuse, K., \& O'Brien, C. (2016). Sentiments, concerns and attitudes towards inclusive education. Zeitschrift für Inklusion, 1/2016. Retrieved from https://www. inklusion-online.net/index. php/inklusiononline/article/view/313

Messiou, K. (2017). Research on the field of inclusive education: Time for a rethink? International Journal of Inclusive Education, 21(4), 146-159.

Milteniene, L., \& Venclovaite, I. (2012). Teacher collaboration in the context of inclusive education. Specialusis ugdymas/Special Education, 27(2), 111-123.

Persson, E. (2013). Raising achievement through inclusion. International Journal of Inclusive Education, 17(11), 1205-1220.

Powell, J. J. W. ([2011] 2016). Barriers to inclusion: Special education in the United States and Germany. Abingdon: Routledge.

Powell, J. J. W. (2014). Comparative and international perspectives on special education. In L. Florian (Ed.), The SAGE handbook of special education (2nd ed.) (pp. 335-349). London: Sage. http://hdl.handle.net/10993/13854

Powell, J. J. W., Edelstein, B., \& Blanck, J. M. (2016). Awareness-raising, legitimation or backlash? Effects of the UN CRPD on education systems in Germany. Globalisation, Societies and Education, 14(2), 227-250.

Powell, J. J. W., Limbach-Reich, A., \& Brendel, M. (2017). Grand Duchy of Luxembourg. In: M. L. Wehmeyer \& J. R. Patton (Eds.), The Praeger handbook of special education (vol. 2: Europe, pp. 296-309). Santa Barbara, CA: Praeger.

Prengel, A. (2016). Humane structures in inclusive education foster development and achievement. In Teaching Diverse Learners in (School) Subjects. USB flash drive. Ludwigsburg, Germany: TdiverS.

Richardson, J. G. \& Powell, J. J. W. (2011). Comparing special education: Origins to contemporary paradoxes. Stanford: Stanford University Press.

Saleh, L. (2004). Desde Torremolimos a Salamanca y ms all. Un tributo a España. In: 
G. Echeita \& M. A. Verdugo, La Declaración de Salamanca sobre NEE 10 años después. Valoración y prospectiva (pp. 23-34). Salamanca: INICO.

Schuller, T., Baron, S. \& Field, J. (2000). Social capital: A review and critique. In S. Baron, J. Field, \& T. Schuller (Eds.), Social capital: Critical perspectives (pp. 1-38). Oxford: Oxford University Press.

Sigurðardóttir A. K., Guðjónsdóttir, H. \& Karlsdóttir, J. (2014). The development of a school for all in Iceland: Equality threats and political conditions. In U. Blossing, G. Imsen, \& L. Moos (Eds.), The Nordic education model (pp. 95-113). Heidelberg, Germany: Springer.

Simón, C., Sandoval, M., Echeita, G., Calero, C., Nuñez, B., de Sotto, P., Pérez, M. M., \& García de la Torre, A. B. (2016). Transformando la 'gramtica escolar' para ser ms inclusivos: La experiencia de tres centros educativos. Contextos Educativos. Revista de Educación, 19, 7-24.

TdiverS (2015, 2016, 2017). Annual reports. http://www.tdivers.eu/downloads/

Tomlinson, S. (2017). A sociology of special and inclusive education. Abingdon: Routledge.

Tyack, D. \& Cuban, L. (1995). Tinkering toward utopia. Cambridge, MA: Harvard University Press.

UNESCO (1994). The Salamanca statement and framework for action on special needs education. Paris: UNESCO.

United Nations (2015). 2030 Agenda for sustainable development. http://www.un.org/sustainabledevelopment/development-agenda/

Zapp, M., Marques, M., \& Powell, J. J. W. (2018). European educational research (re) constructed. Oxford: Symposium Books. 